\title{
Puerperal Thromboembolic Disease in "High Risk" Cases
}

\author{
PETER JACKSON
}

British Medical fournal, 1973, 1, 263-264

\section{Summary}

One hundred obstetric patients were studied for evidence of puerperal thromboembolic disease. Only one case of deep vein thrombosis was detected in patients thought to be in a "high risk" category because of age or operative intervention. Clinical findings were unreliable compared with measurements of ${ }^{125}$ I-labelled fibrinogen uptake. Doppler ultrasound flow detection proved a simple screening technique but produced no abnormal findings in this series.

\section{Introduction}

The commonest cause of maternal death is pulmonary embolism if deaths from abortion are excluded (Department of Health and Social Security, 1972). Most deaths from pulmonary embolism occur without warning symptoms or signs of thromboembolic disease. It remains the duty of the obstetrician to reduce the numbers of these deaths and he must, therefore, find a suitable method for making an earlier diagnosis of thromboembolic disease.

The use of radioactive fibrinogen, first described by Hobbs and Davies (1960), has now proved itself as the most accurate method of detecting thrombosis peripheral to the inguinal region (Browse, 1969). This method of investigation has shown that deep vein thrombosis occurs in at least one-third of patients aged over 40 after a surgical operation (Flanc et al., 1968; Negus et al., 1968; Kakkar et al., 1970a; Lambie et al., 1970; Hall and Clark, 1971). In most cases the thrombus does not extend beyond the calf veins and carries no risk of pulmonary embolism (Kakkar et al., 1969). However, the test does allow the thrombus to be monitored and hence treatment can be started early if extension occurs.

Clinical signs are unreliable in thromboembolic disease. Lambie et al. (1970) showed that signs of deep vein thrombosis are present in only one-third of those with a thrombus diagnosed by the ${ }^{125}$ I-labelled fibrinogen test, and they were also present in one-quarter of the patients with no deep vein thrombosis. The use of Doppler ultrasound flow detection described by Strandness et al. (1967) is more reliable than clinical signs, and when abnormal flow is detected it correlates well with phlebography (Evins, 1970; Sigel et al., 1970; Yao et al., 1972). Unlike the fibrinogen technique it can be used to assess the pelvic veins.

These two tests have been used to study 100 obstetric patients in groups traditionally thought to be at risk from thrombosis.

\section{Patients and Methods}

Three groups of patients were selected-women undergoing tubal ligation in the early puerperium, women delivered by caesarean section, and women aged 30 or more who delivered vaginally. Only patients expected to stay in hospital for a week after delivery were used, and because a radioactive compound was involved women wishing to breast feed were not tested.

\section{St. Mary's Hospital, Manchester M13 0JH}

PETER JACKSON, M.R.C.o.G., Divisional Registrar (Present appointment: Senior Registrar, Leeds University Hnspital, Leeds LS9 7TF)
Consecutive cases in these categories were taken to eliminate any bias in selection, and the study was continued until 100 completed records had been obtained. None of these patients received oestrogens and none had systemic disease.

An intravenous injection of 100 microcuries of ${ }^{125} \mathrm{I}$-labelled fibrinogen, obtained from the Radiochemical Centre, Amersham, was given after delivery. A total dose of $120 \mathrm{mg}$ of potassium iodide was given daily for the duration of the patient's stay in hospital to block the uptake of the isotope by the thyroid gland. The first dose of potassium iodide was given at least two hours before the injection of the ${ }^{125} \mathrm{I}$-labelled fibrinogen. Radioactivity counts were taken at $7 \cdot 5-\mathrm{cm}$ intervals down the medial sides of the patient's legs using a portable isotope localization monitor (Pitman model 235). A count raised by $20 \%$ or more over adjacent points or over the corresponding point on the other leg was taken to indicate thrombosis (Kakkar et al., 1970b; Pai and Negus, 1971).

Doppler ultrasound flow detection was carried out with a beam of $5 \mathrm{~Hz} / \mathrm{sec}$ (Doptone). With the probe over the common femoral vein the spontaneous flow sounds were identified and the presence of diminution in flow with inspiration was noted. Augmentation flow sounds were produced by squeezing the calf, lower thigh, and upper thigh as described by Sigel et al. (1968).

Each patient was examined clinically, and radioactivity counts were taken on alternate days for a minimum of six days. Investigation by Doppler ultrasound was carried out at least once on every patient. All the observations were made by one observer.

\section{Results}

${ }^{125}$ I-labelled Fibrinogen.-There were four positive results with the ${ }^{125} \mathrm{I}$-labelled fibrinogen (table I). In three of these cases there were clinical signs of superficial thrombophlebitis in the area where the radioactivity counts were increased. All three had varicose veins. The fourth case was an obese woman aged 33 with varicose veins who was sterilized on the third day after the birth of her eighth baby. On the day after the operation there were increased radioactivity counts in her left thigh corresponding to signs of superficial thrombophlebitis but there were also increased counts in the left calf indicating deep vein thrombosis.

TABLE I-Results of ${ }^{125}$ I-labelled Fibrinogen Test

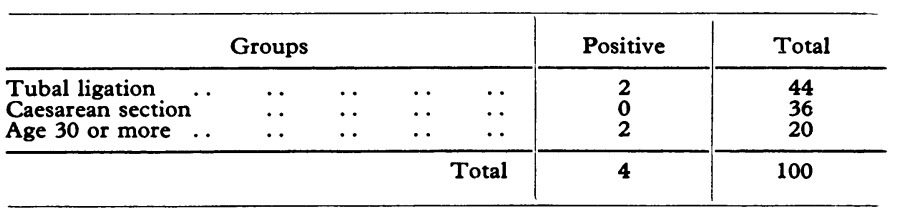

Doppler Ultrasound.-Augmented flow sounds were present in the common femoral vein in all cases. Diminution in the spontaneous flow sounds with inspiration was detected in less than half of the patients but in all cases the flow pattern in the two legs was identical.

Clinical Evaluation.-The four patients with superficial thrombophlebitis detected by ${ }^{125}$ I-labelled fibrinogen all had classical signs of a painful hard segment of vein which was hot and tender. The patient who also had a deep vein thrombosis developed calf pain and tenderness 48 hours after the scan became positive in the calf. In 13 patients with negative isotope 
scans there were positive signs suggestive of deep vein thrombosis. These signs consisted of calf pain, tenderness, or the sudden occurrence of oedema, and in seven cases there were two or more signs present (table II). Homan's sign and increased skin temperature were not found in any of these cases.

TABLE II-Physical Signs when Fibrinogen Test is Normal

\begin{tabular}{|c|c|c|c|c|c|}
\hline & Groups: & $\begin{array}{c}\text { Tubal } \\
\text { Ligation }\end{array}$ & $\begin{array}{c}\text { Caesarean } \\
\text { Section }\end{array}$ & $\begin{array}{l}\text { Age } 30 \\
\text { or more }\end{array}$ & \\
\hline $\begin{array}{l}\text { Pain + tenderness + oedema } \\
\text { Pain + tenderness/oedema } \\
\text { Oedema + tenderness } \\
\text { Oedema alone }\end{array}$ & $\begin{array}{l}\because \\
\cdots \\
\cdots\end{array}$ & $\begin{array}{l}0 \\
1 \\
0 \\
4\end{array}$ & $\begin{array}{l}0 \\
0 \\
1 \\
1\end{array}$ & $\begin{array}{l}2 \\
2 \\
1 \\
1\end{array}$ & $\begin{array}{l}2 \\
3 \\
2 \\
6\end{array}$ \\
\hline & Total & 5 & 2 & 6 & 13 \\
\hline
\end{tabular}

\section{Discussion}

This series shows that deep vein thrombosis is a rare event in the puerperium even in "high risk" cases. It also shows the fallacy of making a diagnosis of calf vein thrombosis on clinical signs alone. In this study signs were present in the calves of 13 women with normal ${ }^{125} \mathrm{I}$-labelled fibrinogen tests.

The incidence in this series is much lower than the insidence of occult thrombosis in general surgical cases. One reason for this may be age. The mean age for this series was 30.8 years (range 16-44 years) whereas surveys on surgical patients have generally dealt with patients over 40 years. Another factor may be the increased mobility of obstetric patients and the need to be up and caring for a child. This cannot be a predominant factor, however, because thrombosis is usually initiated during surgery (Flanc et al., 1968; Negus et al., 1969; Kakkar et al., 1970a).

Oestrogens were not given to any patient in this series and they have been stated to cause an increased incidence of thromboembolism in the puerperium (Daniel et al., 1967; Jeffcoate et al., 1968). It is interesting to note that Friend and Kakkar (1970) when using ${ }^{125} \mathrm{I}$-labelled fibrinogen and phlebography found three cases of deep vein thrombosis in 80 puerperal women who had all been given hexoestrol dipropionate to suppress lactation. The fact that the patients they reported had a mean age 5 years younger than those in this series and had had normal deliveries substantiates the fact that oestrogen predisposes to deep vein thrombosis.

${ }^{125}$ I-labelled fibrinogen provides an ideal screening method for the detection of leg vein thromtosis in high risk cases. Doppler ultrasound flow detection is simple and convenient but only reliable if occlusion of the major veins is present. It can be used during pregancy and in breast feeding mothers whereas the radioactive fibrinogen test cannot. The presence of alteration of the spontaneous flow sounds with respiration was variable and probably represented partial proximal venous occlusion from the enlarged uterus. Sigel et al. (1970) also stated that little reliance should be placed on spontaneous flow sounds, and it seems that only the presence of augmented flow sounds should be determined in routine screening.

The ${ }^{125} \mathrm{I}$-labelled fibrinogen test cannot be recommended for routine screening in the puerperium because of the low incidence of leg vein thrombosis. It is valuable in excluding thromboembolic disease in patients with signs suggestive of deep vein thrombosis, thus avoiding unnecessary anticoagulation. It is speculative as to what percentage of emboli arise from pelvic veins in obstetrics and the Doppler ultrasound is a practical way of screening for pelvic vein thrombosis.

I am particularly grateful to Dr. D. W. Warrell for his help and encouragement. I also thank Professor W. I. C. Morris and the consultant obstetricians at St. Mary's Hospital, Manchester, for allowing me to study patients under their care.

\section{References}

Browse, N. (1969). British Medical Gournal, 4, 676.

Daniel, D. G., Campbell, H., and Turnbull, A. C. (1967). Lancet, 2, 287.

Department of Health and Social Security (1972). Report on Confidential Enquiries into Maternal Deaths in England and Wales, 1967-1969. London, H.M.S.O.

Evans, D. S. (1970). British fournal of Surgery, 57, 726.

Flanc, C., Kakkar, V. V., and Clarke, M. B. (1968). British fournal of Surgery, 55, 742 .

Friend, J. R., and Kakkar, V. V. (1970). fournal of Obstetrics and Gynaecology of the British Commonwealth, 77, 820 .

Hall, C. M., and Clark, C. G. (1971). British fournal of Surgery, 58, 101.

Hobbs, J. T., and Davies, J. W. L. (1960). Lancet, 2, 134.

Jeffcoate, T. N. A., Miller, J., Roos, R. F., and Tindall, V. R. (1968). British Medical fournal, 4, 19.

Kakkar, V. V., Howe, C. T., Flanc, C., and Clarke, M. B. (1969). Lancet, 2, 230.

Kakkar, V. V., Howe, C. T., Nicolaides, A. N., Renney, J. T. G., and Clarke, M. B. (1970a). American fournal of Surgery, 120,527.

Kakkar, V. V., Nicolaides, A. N., Renny, J. T. G., Friend, J. R., and Clarke, M. B. (1970b). Lancet, 1, 540 .

Lambie, J. M. et al. (1970). British Medical Fournal, 2, 142

Negus, D., Pinto, D. J., and Brown, N. (1969). Lancet, 1, 220.

Negus, D., Pinto, D. J., LeQuesne, L. P., Brown, N., and Chapman, M. (1968). British fournal of Surgery, 55, 835 .

Pai, B. Y., and Negus, D. (1971). Lancet, 2, 1098.

Sigel, B. et al. (1970). Archives of Surgery, 100, 535.

Sigel, B. et al. (1970). Archives of Surgery,

Sigel, B. et al. (1968). Surgery, 64, 332 .

. American Fournal of Surgery, 113, 311.

Yao, S. T., Gourmos, C., and Hobbs, J. T. (1972). Lancet, $1,1$.

\title{
Hyperinfection Syndrome with Strongyloides Stercoralis in Malignant Lymphoma
}

\author{
MALCOLM ADAM， OWEN MORGAN， CLEMENT PERSAUD，WILLIAM N. GIBBS
}

British Medical fournal, 1973, 1, 264-266

\section{Summary}

Hyperinfection with Strongyloides stercoralis occurred in three patients with malignant lymphoma. The probable cause in each case was alteration of the immune responses

University of the West Indies, Kingston, Jamaica

MALCOLM ADAM, M.B., M.R.C.P., Lecturer, Department of Medicine OWEN MORGAN, M.D., M.R.C.P., Lecturer, Department of Medicine CLEMENT PERSAUD, M.SC., Resident Microbiologist

WILLIAM N. GIBBS, M.R.C.PATH., Lecturer, Department of Pathology either as a result of the malignant lymphoma or by the treatment given. Though thiabendazole (Mintezol) has produced reasonable results in the treatment of the hyperinfection syndrome, preliminary data suggest that the new broad-spectrum anthelmintic levamisole (Ketrax) is more effective. All patients who live or have lived in an area where strongyloidiasis is endemic should be investigated to detect the presence of the nematode before and during treatment with drugs with immunosuppressive properties. In view of the high mortality with S. stercoralis hyperinfection, vigorous therapy should be instituted before the use of immunosuppressive drugs. 